This is a peer-reviewed, accepted author manuscript of the following paper: Gandhi , A. M., Shanmugan, S., Gorjian, S., Pruncu, C., Sivakumar, S., Elsheikh, A. H., Essa, F. A., Omara, Z. M., \& Panchal, H. (2021). Performance enhancement of stepped basin solar still based on OSELM with traversal tree for higher energy adaptive control. Desalination, 502, [114926].

https://doi.org/10.1016/i.desal.2020.114926

\title{
Performance enhancement of stepped basin solar still based on OSELM with traversal tree
} for higher energy adaptive control

\section{A. Mohandass Gandhi a, i, S. Shanmugan ${ }^{\text {a }}$, Shiva Gorjian ${ }^{c}$, Catalin I. Pruncu ${ }^{\mathrm{d}, \mathrm{e}}$, S. Sivakumar ,} Ammar H. Elsheikh ${ }^{g}$ F.A. Essa ${ }^{\text {h }}$ Z.M. Omara ${ }^{\text {, Hitesh Panchal }}{ }^{j}$

a Research Scholar, Department of Physics, Koneru Lakshmaiah Education Foundation, Green Fields, Guntur District, Vaddeswaram, Andhra Pradesh 522502, India

${ }^{b}$ Research Centre for Solar Energy, Department of Physics, Koneru Lakshmaiah Education Foundation, Green Fields, Guntur District, Vaddeswaram, Andhra Pradesh 522502, India.

'⿳亠口冋口灬 Biosystems Engineering Department, Faculty of Agriculture, Tarbiat Modares University (TMU), Tehran, Iran.

${ }^{\mathbf{d}}$ Department of Mechanical Engineering, Imperial College London, Exhibition Rd., London, UK

e Design, Manufacturing \& Engineering Management, University of Strathclyde, Glasgow G1 1XJ, Scotland, UK,

${ }^{\mathbf{f}}$ Department of Computer Science and Engineering, Koneru Lakshmaiah Education Foundation, Green Fields, Guntur District, Vaddeswaram, Andhra Pradesh 522502, India.

g Department of Production Engineering and Mechanical Design, Tanta University, Tanta 31527, Egypt

h Mechanical Engineering Department, Faculty of Engineering, Kafrelsheikh University, Kafrelsheikh 33516, Egypt.

${ }^{\mathrm{i}}$ Muthayammal College of Arts \& Science (Affiliated to Periyar University - A Unit of VANETRA Group),

Vengayapalayam, Kakkaveri, Rasipuram, Namakkal, Tamil

Nadu 637408, India

${ }^{j}$ Mechanical Engineering Department, Government Engineering College, Patan 384265, Gujarat, India

E-mail IDs: (Shanmugan) s.shanmugam1982@gmail.com, (Shiva)Gorjian@modares.ac.ir,

(Pruncu) c.pruncu@imperial.ac.uk, (Sivakumar) sivas.postbox@gmail.com,

(Ammar)ammar_elsheikh@f-eng.tanta.edu.eg, (Essa) fadlessa@eng.kfs.edu.eg,

(Omara) Zm_omara@yahoo.com.

*Corresponding author Email ID: s.shanmugam1982@gmail.com.

\begin{abstract}
A basin solar still precision design is regularly not reachable. To solve this issue, the basin area is coated with a nanolayer which allows to stimulate and control the multifaceted of the fast evaporations of physiognomies. The use of adaptive neural network-based approaches leads to better design cause permits detecting the conjunction, gigantic period feed, lower performances parameters which can be detrimental to system production. Further, an online Sequential Extreme Learning Machine (OSELM) system can be used to obtain the latest solar still based on adaptive control. Here, the solar still has been created at physical scale activity for haste of energy
\end{abstract}


absorption. The performance of solar still are defined by the uniform occurrence with time series of dynamics transfer from basin liner to saline water. The feasibility scheme to authenticate were studied by applying calculation to the extensive heat transfer process. The furious $\mathrm{SiO}_{2} / \mathrm{TiO}_{2}$ nanoparticles used for the stepped basin solar still (SBSS) efficiency shows an increase of performances by $37.69 \%$ and $49.21 \%$, respectively using $20 \%$ and $30 \%$ of $\mathrm{SiO}_{2} / \mathrm{TiO}_{2}$ coating. It is comparable higher when equated against an SBSS coating either $\mathrm{SiO}_{2}$ or $\mathrm{TiO}_{2}$, and/or no nanoparticles coatings. The binary search tree enabled to find the optimal cost for the solar still investigated and obtaining a superior design with higher performances.

Keywords: Stepped basin solar still; Nanomaterials; OSELM; Adaptive tree traversal.

\section{Introduction}

In an original solar still, heat trapped inside an enclosure where the internal air temperature may reach nearly $120^{\circ} \mathrm{C}$ that would be sufficient to evaporation or bake basin nanolayer. Industrial process monitoring for real-world applications in financial data was analyzed elements of prediction and buyer performance estimates. Perez et al., [1] studied an online learning algorithm for flexible topologies and implementations of a neural networks system. It is the samples to attain continuity in the method for statistics brook. Qiao et al., [2] developed the non-line self-adaptive modular neural network and time series control ways. They made use of the underlying distribution or a movement with the data vicissitudes concluded time. Lughofer [3] studied an online learning algorithm which was selected the more appropriate assortment done group updated to acquire new knowledge for changing patterns in evolving data stream by Zhang et al., [4] and Zhou et al., [5]. Suresh and Shanmugan [6] have developed basin solar still and was used in flowing water with PCM-nanoparticles. It concluded that the efficiency of the system was FWCW of 70.02\%. 24hours yield of solar still has produced of $9.429 \mathrm{~kg} \mathrm{~m}^{-2} \mathrm{day}^{-1}$.

Zanganeh et al., [7] were produced an improve solar still and have coated in nano-silicon solution with giving a dip-coating technique. It utilizes that nano-coating caused condensate making of solar still to higher significantly. They are monitored by AFM tests exposed that surface roughness of the glass covers moves to drip. Suresh et al., [8] have considered the thermal performance of a single basin solar still. The sullage water treatment fuzzy logic techniques used to produce clean water from the energy of the sun. It concluded that the 24 hours cycle for yield is $7.624 \mathrm{~kg} / \mathrm{m}^{2}$ day 
and without drip $5.254 \mathrm{~kg} / \mathrm{m}^{2}$ day. The overall efficiency is $45 \%$ for a hybrid nano-black paint increases the temperatures of $66^{\circ} \mathrm{C}$. Zanganeh et al., [9] have produced in solar still and have used in the condensation surface for coated by nanomaterials to improve the condensation process. It is improved the productivity of solar still at cover tilt angles of $35^{\circ}$ and $45^{\circ}$. Abdullah et al., [10] was studied that an internal reflector on the tray's distiller performance. They are used in nano-coating on the tray's distiller performance and have developed in PCM - paraffin wax $+\mathrm{CuO}$ nanoparticle. It found that the efficiency of trays still of $51.5 \%$ associated with $35 \%$ for conventional solar still. The condensation process prepared by Zanganeh et al., [11] plays a critical role in the efficiency of solar stills. They are coated on the condensation surface in titanium dioxide and silicon nanoparticles and changed the surface of wettability. It the condensing surface increases the productivity of 10-35\%. Shanmugan et al., [12] have improved the basin solar still and was used in $\mathrm{Al}_{2} \mathrm{O}_{3}$ and $\mathrm{C}_{18} \mathrm{H}_{36} \mathrm{O}_{2}$ basin area by a drip button to pour saline water drop by drop on absorbing materials in the basin. It concluded that the efficiency of the still of 59.14\% (summer) and 27.13\% (winter). They are recognized by the FWCW using a basin is on the solar still. Agrawal et al., [13] have expected the theoretical and experimental results obtained for a single sloped basin type solar still. They are discussed for theoretical, and the experiment with daily efficiency of $2 \mathrm{~cm}$ and $10 \mathrm{~cm}$ basin water depths is around $52.83 \%$ and $41.75 \%$ and was $41.49 \%$ and $32.42 \%$ respectively. Arunkumar et al., [14] have studied in nano-coated $\mathrm{CuO}$ absorbers with PVA sponges in the basin of the solar still. They are synthesized by the thermal evaporation method used in $\mathrm{CuO}$ nanoparticles coated absorber plates by the system. Absorber plates are coated in $\mathrm{CuO}$ nanoparticles with PVA sponges and have improved the yield of $26 \%$.

Saleh et al., [15] were synthesized using Hydrothermal method by using $\mathrm{ZnO}$ nanoparticles and verified in solar still. The $\mathrm{ZnO}$ non-materials concentration of the solar still resulting in an oxide nanomaterials nano-rod was $100 \mathrm{~nm}$ lengths, $10-15 \mathrm{~nm}$ diameters and nano-sphere are $250 \mathrm{~nm}$ diameters have been studied. It found that nano-rod shape achieves a range of $30 \%$ and $38 \%$ of productivity increases in solar still. Mahmoud et al., [16] have indicated that the daily productivity of stored energy integrated basin solar still. The solar still acceptable for the product is determined about $11 \mathrm{~L} / \mathrm{m}^{2}$ by using Glauber's salt with $10 \%$ volume fraction of $\mathrm{CuO}$-nanoparticles in $\mathrm{CR}=2$, $\mathrm{h}=0.1 \mathrm{M}$. The basin water temperature is achieved at $70^{\circ} \mathrm{C}$ to prevent potential scale development. 
Wang et al., [17] have analyzed in double metal-dielectric (cermet) solar selective absorber coatings (SSACs) and used in co-sputtering techniques with multiple targets. They suggest in multilayer SSACs exhibit good solar absorptance of 0.93 and were low thermal emittance of 0.06 . It concluded that the shows an ideal spectral selectivity of $0.92 / 0.07$. The SSAC was a gifted absorber for stable thermal harvesting in solar vacuum collectors.

Isabel et al., [18] coated gel-dipping with polysaccharides and prepared $\mathrm{TiO}_{2}$ photocatalytic materials. They used excellent performance for the photocatalytic activity of the final coated tiles was described and conversed. The painted all properties are analyzed for the need to move the photocatalytic action of the coatings. Hualong Liu et al., [19] coated by the use of $\mathrm{TiO}_{2} / \mathrm{WO}_{3}$ a magnetic nanoparticle and was the absorption of visible light (solar light). Sixteen catalysts quickly mineralized and ten dyes under the focus of sunlight. It found that recycling with a magnet excellent reusability. Sharshir et al., [20] were conducted with an energy and exergy analysis of solar still thermal performance with micro/nanoparticles. MSSs energy efficiency of graphite, $\mathrm{CuO}$ was $41.18 \%$ and $38.61 \%$, then CSS is $29.17 \%$. The yield of the MSSs has increased energy in graphite, $\mathrm{CuO}$ to $41.18 \%$ and $32.35 \%$. The exergy efficiency of MSSs is $4.32 \%$ and $3.78 \%$, while exergy efficiency for CSS was $2.63 \%$.

Rashidi et al. [21] have developed by reviewing the literature on implementing nanofluid technology in active and passive solar distillation systems. The review designates are daily productivities of solar distillation systems enhanced by nanofluid and increasing the volume fraction of nanoparticles. Rashidi et al. [22] were proposed the volume of fluid (VOF) model to investigate the potential of $\mathrm{Al}_{2} \mathrm{O}_{3}$-water nanofluid to improve the productivity of single slope solar still. VOF model was used to simulate the evaporation-condensation phenomena. The efficiency of solar still was increased by $25 \%$ using nanofluid by volume fraction of $5 \%$. The maximum entropy generation has happened close to the bottom and top surfaces of the system. Rashidi et al. [23] were developed with nanofluid on the productivity of stepped solar still. The sensitivity analysis is determined the hourly productivity of height and length steps. It was conculcated that the optimization analysis of the surface method optimized the geometry of stepped inside the still. The solar still was indicated that of $22 \%$ enhancement that yield of nanoparticle ratios from $0 \%$ to $5 \%$ and $2.1 \%$ of the RSM and CFD calculated to best result of $2.1 \%$. 
Rashidi et al. [24] performed an experimental analysis of exergy investigated by a reticular porous insert with improvement on single slope solar still. The hourly productivity of the solar still progresses by inserting the reticular porous layer in the basin. The exergy efficiency has improved that system by $7.33 \%$.

Various scientists have documented the use of furious $\mathrm{SiO}_{2} / \mathrm{TiO}_{2}$ nanoparticle original familiarizes that of limits production on solar thermal applications. The current study aims of a solar still are enhanced thermal performance of the system. It advances the SBSS has coated with a bar plate that used in doping $\mathrm{SiO}_{2} / \mathrm{TiO}_{2}$ nanoparticle at a different ratio of 10 to $50 \%$. The SBSS has studied built on adaptive control through an online Sequential Extreme Learning Machine (OS-ELM). The central part of a binary search trees authorization and originate a limit of the cost optimum by a solar still and developed with previous significance.

\section{Experimental materials and methodology}

\subsection{Analysis of SBSS performance methods}

SBSS analysis of a new performance of an experimental method and the schematic diagram shown in Figs. 1(a) \& 1(b) as by Feilizadeh et al., [21]. The solar still has an area of $100 \mathrm{~cm}$. The length*breadth of the dimensions of the absorption area is $100 \mathrm{~cm} * 100 \mathrm{~cm}$. The front wall height is $25 \mathrm{~cm}$. The height of the back wall is $30 \mathrm{~cm}$. It is comprised of a total 16 stepped absorber basin plates fixed inner side with the left side of 8 plates and right sides for 8 plates on the design. It consisted of the absorber basin area in the copper sheet and that the inner stepped basin plate has used in a mild steel sheet with an analysis of preliminary steps. The transmission glass cover thickness of the material is $4 \mathrm{~mm}$ used in the system. The side walls and bottom of the basin were insulated with the glass wool. The glass wool's thermal insulating material (fiberglass) has used the system increases in moisture content, causing a significant increase in thermal conductivity of $0.040 \mathrm{~W} / \mathrm{mK}$.

The SBSS has fabricated in the same dimensions different from the proposal presented by Salarabadi, and Rahimi [22]; Rahbar et al. [23], which used nanoparticles of furious $\mathrm{SiO}_{2}, \mathrm{TiO}_{2}$, mixture furious $\mathrm{SiO}_{2} / \mathrm{TiO}_{2}$, without nanoparticle (conventional solar still). It was studied, and the results compared to the nanoparticles with the effect of different solar still performances. The 
experimental work started at 09.00 am to $17.00 \mathrm{pm}$ and variations of the parameters like temperatures of the stepped basin, saline water, moist internal air and glass cover measured at 30 minutes time interval the experiment conducted under the weather condition of KLEF at Vijayawada, Andhra Pradesh. The solar radiation data was measured using the TENMARS TM206 solar power meter. The SBSS data were taken in order to a laptop to identify the system. The standard solar power meter measured all the parameters of different cookers are an indicator of 6channel measure the temperature. It measured the RTD - PT-100 type with sensor absorption of the thermocouple wire in range $0-800^{\circ} \mathrm{C}$ with $\pm 0.1^{\circ} \mathrm{C}$ correctness of the data separately on the systems.

In the presented study, the integration of nanoparticles aimed to increase the absorbed energy by the SBSS and resulted in output with higher quality. Therefore, to determine the performance of the system. The nanolayer occupied the internal energy presented as follows;

Energy balance equations for the temperature elements of the still have been written and the following assumptions have been considered

(i) There is no vapour leakage from the SBSS

(ii) As the thickness of the condensing glass cover is small, there is no temperature gradient throughout the surface

(iii) Due to small inclination of the condensing glass cover, both evaporating and condensing surfaces are considered to be parallel to each other

\subsection{Energy Balance equations}

For glass cover:

$\alpha_{\mathrm{g}} T_{\text {srg }} l_{g} b_{g}+h_{1}\left(T_{w-} T_{g}\right) A_{e f f}=h_{2}\left(T_{g}-T a\right) l_{g} b_{g}$

where

$h_{1}=h_{e w g}+h_{r w g}+h_{c w g}$

$h_{2}=h_{c g a}+h_{r g a}$

$h_{c w g}=0.884 \times\left[\left(T_{w}-T_{g}\right)+\frac{\left(P_{w}-P_{g}\right)\left(T_{w}+273\right)}{268.9 \times 10^{3}-P_{w}}\right]^{1 / 3}$

$h_{r w g}=\varepsilon_{e f f} \sigma\left[\left(T_{w}+273\right)^{2}+\left(T_{g}+273\right)^{2}\right]$

$h_{\text {ewg }}=0.0163 \times h_{c w g}$ 


$$
\begin{aligned}
& h_{r g a}=\varepsilon_{g} \sigma\left[\left(T_{g}+273\right)^{4}-\left(T_{a}+261\right)^{4}\right] \\
& h_{c g a}=5.7+3.8 v
\end{aligned}
$$

For Stepped basin surface:

$\alpha_{\mathrm{g}} \tau_{g} T_{s r g} l_{g} b_{g}=M_{w} \frac{d T_{w}}{d t} A_{e f f}+h_{1}\left(T_{w}-T_{g}\right) A_{e f f}+h_{3}\left(T_{w}-T_{a}\right) A_{e f f}$

where

$h_{3}=L / k$

From Eq. 1, $T_{g}$ can be written as

$$
T_{g}=\frac{\alpha_{\mathrm{g}} T_{s r g} l_{g} b_{g}+h_{1} T_{w} A_{e f f}+h_{2} T a l_{g} b_{g}}{h_{1} A_{e f f}+h_{2} l_{g} b_{g}}
$$

Substituting for $T_{g}$ in Eq. (2) and can be written as

$$
\begin{aligned}
& \alpha_{w} \tau_{g} T_{s r g} l_{g} b_{g}=M_{w} \frac{d T_{w}}{d t} A_{e f f}+h_{1}\left(T_{w}-\left\{\frac{\alpha_{g} T_{s r g} l_{g} b_{g}+h_{1} T_{w} A_{e f f}+h_{2} T_{a} l_{g} b_{g}}{h_{1} A_{e f f}+h_{2} l_{g} b_{g}}\right\}\right) A_{e f f}+ \\
& h_{3}\left(T_{w}-T a\right) A_{\text {eff }}
\end{aligned}
$$

After suitable rearrangement, the equation can be written as

$$
\begin{aligned}
& \frac{\alpha_{w} \tau_{g} T_{\text {srg Aeff }}}{M_{w} \text { Aeff }}+\frac{h_{1} \alpha_{g} T_{\text {srg }} l_{g} b_{g} \text { Aeff }}{M_{w} A_{\text {eff }}\left(h_{1} \text { Aeff }+h_{2} l_{g} b_{g}\right)}-T_{a}\left[\frac{h_{1} h_{2} l_{g} b_{g} \text { Aeff }}{M_{w} A_{\text {eff }}\left(h_{1} \text { Aeff }+h_{2} l_{g} b_{g}\right)}-\frac{h_{3} A_{e f f}}{M_{w} \text { Aeff }}\right]=\frac{d T_{w}}{d t}+ \\
& T_{W}\left[\frac{h_{1} \text { Aeff }}{M_{w} \text { Aeff }}-\frac{h_{1}{ }^{2} A_{\text {eff }}^{2}}{M_{w} A_{\text {eff }}\left(h_{2} l_{g} b_{g}\right)}+\frac{h_{3} A_{\text {eff }}}{M_{w} \text { Aeff }}\right]
\end{aligned}
$$

Eq. 5 resembles the form

$$
\frac{\mathrm{dT}_{\mathrm{w}}}{\mathrm{dt}}+\mathrm{PT}_{\mathrm{w}}=\mathrm{Q}
$$

Where,

$$
\begin{aligned}
& P=\frac{h_{1} h_{3}}{M_{w}}-\frac{h_{1}{ }^{2} A_{e f f}}{M_{w} A_{e f f}\left(h_{2} l_{g} b_{g}\right)} \\
& Q=\frac{\alpha_{w} \tau_{g} T_{s r g}}{M_{w}}+\frac{h_{1} \alpha_{g} T_{s r g} l_{g} b_{g}}{M_{w}\left(h_{1} A_{e f f}+h_{2} l_{g} b_{g}\right)}-T_{a}\left[\frac{h_{1} h_{2} l_{g} b_{g}}{M_{w}\left(h_{1} A_{e f f}+h_{2} l_{g} b_{g}\right)}-h_{3} A_{e f f}\right]
\end{aligned}
$$

The solution of Eq. 6 can be written as

$$
\mathrm{T}_{\mathrm{w}} \cdot \mathrm{e}^{\mathrm{Pt}}=\frac{\mathrm{Q}}{\mathrm{P}} \cdot \mathrm{e}^{\mathrm{Pt}}+\mathrm{C}
$$

When $\mathrm{t}=0, T_{w}=T_{w 0}$

Therefore $\mathrm{C}=\mathrm{T}_{\mathrm{w} 0}-\frac{\mathrm{Q}}{\mathrm{P}}$ 
Substituting the value of $\mathrm{C}$ in Eq. 7, we get

$$
\mathrm{T}_{\mathrm{w}}=\frac{\mathrm{Q}}{\mathrm{P}}+\left(\mathrm{T}_{\mathrm{w} 0}-\frac{\mathrm{Q}}{\mathrm{P}}\right) \mathrm{e}^{-\mathrm{Pt}}
$$

Analytical solutions for stepped basin and glass cover temperature have been used to evaluate the instantaneous distillate yield and efficiency.

The amount of distilled water collected for a unit area is given by.

$$
m_{w}=\frac{h_{\text {ewg }} \times\left(T_{w}-T_{g}\right) \times 3600}{L} \mathrm{~kg} / \mathrm{m}^{2} \mathrm{hr}
$$

The instantaneous efficiency of the still is given by.

$$
\eta_{\text {inst }}(\%)=\frac{m_{w} \times L}{3600 \times H_{\text {inst }}} \times 100
$$

\subsection{SBSS control energy uses an OSELM:}

The general approach of extreme learning machine (ELM) anticipated by Liang et al. [23] is utilized in several fields. The SBSS used the saline water for weight of the mass and partialities of the covered an initialization ELM. The SBSS developed the least-squares process with the use of parameter values to the considered suitable heaviness of the production coatings. The heat transfer speed is higher than further use in traditional neural networks. This method avoids convergence into local minima Guang et al., [24].

The samples used in $\mathrm{S}$ arbitrary separate physical activity for $\left(\mathrm{X}_{i}, T_{i}\right) \in R^{n} \times R^{m} . \mathrm{X}_{j}$ was the $\mathrm{n} \times 1$ vector for involvement and $T_{i}$ is $\mathrm{m} \times 1$ vector for goal. The active function of $\mathrm{g}\left({ }^{\circ}\right)$ and the hidden layer of $\mathrm{L}$ used an additive stimulation or Radial Basis Function (RBF) activation or both. The single-hidden layer feedforward neural network (SLFN) approximately given for S working out of the SBSS as zero error with existing for evaporation that are $\omega_{i}, m_{i}$, and $\theta_{i}$,

$$
E=\sum_{i=1}^{l} \theta_{i} g\left(\omega_{i}, m_{i}, X_{i}\right)
$$

where saline water (weights) $\omega_{i}, m_{i}$ then it is followed in biases of a hidden layer. Output based on purification water (weights) vector is $\theta$. We can write as

$$
T=\Phi \theta
$$

where $\Phi, \theta$ expressed for $\mathrm{T}$

$$
\theta=\Phi^{\top} T
$$

Pseudo-inverse based on back point is $\Phi$

$$
\Phi^{*}=\left(\Phi^{\top} \Phi\right)^{-1} \Phi^{\top}
$$




$$
\Phi^{\top}=\left(\Phi^{\top} \Phi\right)^{-1} \Phi^{\top} \mathrm{T}
$$

Where $\operatorname{rank}(\Phi)=\mathrm{L}$ for output water result followed in vector $\theta$ form eq. (7) we can write as

$$
\theta=\left(\Phi^{\top} \Phi\right)^{-1} \Phi^{\top} \mathrm{T}
$$

\subsection{Online sequential extreme learning machine (OSELM) approach for SBSS:}

The heat transfer with an order of more realistic that of the SBSS values was generated line by line or hunk by a hunk of OSELM is followed as ELM. The recursive least square process estimated with a numerical technique as a result (weight) vector $(\theta)$. The OSELM is a significant part of two like (i) initialization (ii) sequential learning. We have followed a way of that process as consider evaporation process of the design $\mathrm{S}=\left\{\left(\mathrm{X}_{i}, T_{i}\right) \nmid \mathrm{X}_{i} \in R^{n} \cdot T_{i} \in R^{m}, i=1, \ldots\right\}$, then $\mathrm{RBF}$ activated function of $\mathrm{g}\left({ }^{\circ}\right)$ these nodes of $\mathrm{L}$ hidden layer.

\section{(i) Initialization:}

The SBSS values to get initial water temperature as $S_{0}=\left(\mathrm{X}_{i}, T_{i}\right)_{i=1}^{S_{0}}$ and $S_{0} \geq \mathrm{L}$ were considered from the initial result vector layer as

$$
\theta^{(0)}=\left(\Phi_{0}^{T} \Phi_{0}\right)^{-1} \Phi_{0}^{T} \mathrm{~T}_{0} \text { where } \mathrm{T}=\left[t_{1} \ldots \ldots \ldots, t_{S_{0}}\right]^{T}
$$

\section{(ii) Sequential Learning}

The SBSS results were generated line by line or hunk by hunk of the heat values of

$S_{k+1}=\left(\mathrm{X}_{i}, T_{i}\right)_{S_{k+1}}^{S_{k}+S_{k+1}}$ and were created with the outcome of matrix function for a hidden layer of $\Phi_{k+1}$.

The SBSS materials (wights - saline water) of the result are

$$
\begin{aligned}
& B_{k+1}=B_{k}-B_{k} \Phi_{k+1}^{T}\left(I+\Phi_{k+1} B_{k} \Phi^{T_{k+1}-1}\right) \Phi_{k+1} B_{k} \\
& \theta^{(k+1)}=\theta^{(k)}+A_{k+1}^{-1} \Phi_{k+1}^{T}\left(T_{k+1}-\Phi_{k+1} \theta^{(k)}\right)
\end{aligned}
$$

Finally, that design performance as a $\mathrm{k}=\mathrm{k}+1$ set of hunk water temperature values is reported sequential learning in development with the conclusion of the SBSS.

\subsection{OSELM neural network adaptive controller on SBSS}

The algorithm of the SBSS is controlled through DO concentration from heat transfer modes and manipulated variable of the solar still is expressed as

$$
Y_{k+1}=f\left(X_{k}\right)+D\left(X_{k}\right) U_{k}+C_{k}
$$

From Eq. (10) heat is transformed according as 


$$
Y_{k+1}=\bar{f}\left[X_{k}, w^{*}\right]+\bar{D}\left[X_{k}, v^{*}\right] U_{k}+\Delta_{f}
$$

where the SBSS is used in perturbation $C_{k}$ and is the sum of $\Delta_{f}$ the showing fault of DO focused that absolute temperature values solar still error and OSELM formed each neural networks as

$$
\begin{gathered}
\bar{f}\left[X_{k}, w^{*}\right]=\sum_{i=1}^{L} w_{i}^{*} g\left(\alpha_{i}, m_{i} X_{k}\right) \\
\bar{D}\left[X_{k}, v^{*}\right]=\sum_{i=L+1}^{2 L} v_{i}^{*} g\left(\alpha_{i}, m_{i} X_{k}\right)
\end{gathered}
$$

The SBSS is updated for OSELM principle as followed an online value gotten in a sequential method

$$
\left\{B_{k}=B_{k-1}-\frac{B_{k-1} \Phi_{k}^{T} \Phi_{k} B_{k-1}}{1+\Phi_{k} B_{k-1} \Phi_{k}} \quad \bar{\theta}_{k+1}=\bar{\theta}_{k}+B_{k} \Phi_{k}^{T} E_{k+1}^{*}\right.
$$

DO concentration of SBSS is controller as

$$
U_{k}=\frac{-\bar{f}\left[X_{k}, w^{*}\right]+Y_{k+1}^{*}}{\bar{D}\left[X_{k}, v^{*}\right]}+Q_{\text {total energy }+N}\left(m_{w}\right)
$$

From control as eq. (17) the energy process of the SBSS uses an OSELM approached in Fig. 2.

\subsection{Analysis of SBSS using Binary Search Tree:}

The binary search trees analysis of a solar still is given in a sequence for $\sigma_{k}=$ $\left(\sigma_{1}, \sigma_{2}, \sigma_{3} \ldots \ldots \sigma_{n}\right)$ and ordered a set of $\mathrm{n}$ distinct elements that energy process. It obtained as following in heat energy process by the binary search tree of $\mathrm{T}\left(\sigma_{k}\right)$, and components are $\sigma_{1}, \sigma_{2}, \sigma_{3} \ldots \ldots \sigma_{n}$ an iteratively involves formerly vacant tree of heat energy. The fundamental problems in computer science solved by binary search trees use of data structures by Aho et al. [25] and Knuth [26]. The solar still is an important data structure in a place and binary search trees area for a central role investigation as algorithms. The SBSS has higher energy levels of $\mathrm{T}\left(\sigma_{k}\right)$ and parameters are considered the heat energy by the level of equal by a Quicksort $\left(\sigma_{k}\right)$ for compounds for the axis by Cormen et al. [27]. Here heat energy developed to reach the solar still by a binary search tree is (n) objective yield of $\sigma_{k}=(1,2, \ldots n)$ and attained from higher energy levels of parameters to transfer energy on the system. The water temperatures are higher in average values of binary search trees and performed to understand the arrangements of energy levels were not wholly haphazard of the system. Haphazardness is partial of the basin area. Finally, the thermal energy saved higher of binary search trees at that solar still to the small chance that partial arbitrariness. 
The binary search trees use of a SBSS is $\mathrm{T}\left(\sigma_{k}\right)$ and the thermal energy transfer rule is the left side wall to the right wall with maxima the order of gain $\sigma=\left(\sigma_{1}, \sigma_{2}, \sigma_{3} \ldots \ldots \sigma_{n}\right)$. The system of a primarily empty tree the roots of $\mathrm{T}\left(\sigma_{k}\right)$ as surveys have a glass cover, stepped basin, water temperature, moist air, product water for $\sigma_{1}$ of $\sigma_{k}$. The design limited $\sigma$ then all parameters value reduced in $\sigma_{1}$, we can write as

$$
\sigma_{k}<=\sigma_{k}\left\{|\boldsymbol{i}| \boldsymbol{\sigma}_{\boldsymbol{i}}<\boldsymbol{\sigma}_{\mathbf{1}}\right\}
$$

It is gained for the energy an inductively as of $\sigma<$.

$\sigma$ is control the parameters increases an analogously $\sigma_{1}$ as

$$
\sigma_{k}>=\sigma_{k}\left\{|\boldsymbol{i}| \boldsymbol{\sigma}_{\boldsymbol{i}}>\boldsymbol{\sigma}_{\mathbf{1}}\right\}
$$

The SBSS is right subtree for $\sigma_{1}$. T $\left(\sigma_{k}\right)$ has gained for an inductively as of $\sigma_{k}>$.

The solar still transmission of heat energy as following in Fig. 3(a), it denoted the higher energy level of T $\left(\sigma_{k}\right)$. The SBSS absorbed an energy level of higher $\left(\sigma_{k}\right)$ and the most extended pathway from the root to a leaf contains several nodes. The internal heat transfer is a maximum level of $\sigma_{\mathrm{i}}$, maxima of $\sigma$ if $\sigma_{i}>\sigma_{j}$ for all parameters are $j \in[i-1]$. The energy was saving that settings of the parameters are $\left(\sigma_{k}\right) \leq$ height $\left(\sigma_{k}\right)$ and amount of heat energy to the maximum value is equivalent to the dimension of the all sidewall pathway in a tree of $\mathrm{T}\left(\sigma_{k}\right)$.

\subsubsection{Assumption by the SBSS}

Binary search tree (BST) is empty or nonempty as the following properties.

> The solar still parameters are BST and must be discrete.

$>$ It is smaller than the root and inserted at the left side of the subtree.

$>$ The setting is larger than the source added at the right side of the subtree.

In a binary search tree, the parameters of the solar still arranged in such a way that for any node the heat energy sources on the left side are smaller than that node and the heat energy source on the right side is more significant than that node. The means that the heat energy in the left subtree is smaller than that key element in the right subtree and is more significant than that essential of the stepped basin solar still. It is easy for searching for key factors. Time taken for searching an element in a tree depends on the higher of the tree.

1. Higher of a binary search tree minimum is $\mathrm{T}\left(\sigma_{k}\right)$.

2. Higher of the binary search tree maximum is $\sigma_{k}$. 
The solar still performs rotation to a convert more gigantic height binary search tree to a smaller height binary search tree.

\subsubsection{Algorithm:}

1. The solar still value to insert starts comparison from the root node.

2. If the feature name is higher than the root, then the comparison moves towards the right subtree.

3. If the feature name is less than the root, then the feature comparison moved towards the left subtree.

4. Then the current node will become as root and the comparison continue until the desired location to insert is found.

\subsubsection{Binary search tree insertion diagram with temperature values by SBSS}

In a binary search tree, we take an element as a root element from the given ingredients. If the considered item is higher than the root element, we insert it on the right subtree, if the aspect which we take is less than the root element we enter it on the left subtree as by Roberto De Prisco [28] and Navin Goyal and Manoj Gupta [29].

\subsubsection{Experiment:}

Intel core $i 58^{\text {th }}$ generation processor is used in the experiment. It has a RAM capacity of 8 Giga Byte and secondary storage capacity of 1 Tera Byte. The temperature measurement in the experiment is performed for duration of one year. The implementation of the experiment is finished with Java Standard Edition version 13. Java Database connectivity is used to access the database. Features and its temperature values are stored in the MySQL version 8.0.4. The reading that take in the experiment is time stamped using a system. A multimeter is a measure of the temperature of different components in the experiment.

\subsubsection{Memory Organization:}

The experiments are performed for one year. We have used two tables, one for "accountant table" and another for "reference table". The "accountant" table has three entries in each Row. Entries in the table contain "timestamp", "feature" and "rtemp". "Timestamp" contains information related to time at which the reading for the experiment is taken, and it is stored as a long integer with Size 8 bytes. "Material" gives information about item saline water in the stove and it is stored as a character of Size 15 bytes. "rtemp" corresponds to the room temperature in which the various 
features reading is taken with a size of 4 bytes. The size of a row in the "reference" table is 27 bytes. In the experiment, when more readings are taken the size of the table increases dynamically. The second table is a mapping table from timestamp to the day of the year. It fixes in length with a capacity of 355 entries. Each entry consists of "day" and "next" field. The "day" field holds a pointer to the day of the year in which the experiment reading is taken. The "next" field points to an address of a linked list. Each entry in the linked list of sizes each entry is 8 bytes, each "day" and "next" field is having a 4 bytes sizes. The overall memory organization of the experimental setup shown in Fig. 3 b.

The linked list consists of a collection of nodes. Each node is composed of three fields viz. "timestamp", "ptr" and "next". The "timestamp" holds the value of time at which the reads have been taken and it is of type long with 8 bytes. Pointer "ptr" is a pointer to a binary search tree that holds a reading of an experiment for various components in the solar still. The "next" is a pointer to a next node in the linked list. The fields "ptr" and "next" each having a size of 4 bytes. So, the total size of a node is 16 bytes.

\subsubsection{Working Principle:}

The reading of water treatment is done in the experiment. The various temperature of water treatment needs to be measured using a multimeter. The time of reading is taken as timestamp from the digital clock. This timestamp, material under consideration and room temperature is recorded in the accountant table. For example, the timestamp "1606979426043" contains the following information as day- ' 12 ', month- ' 3 ', year- ' 2020 ', hour- ' 08 ', minutes- ' 10 ', second' 26 ' and millisecond- ' 43 '. This timestamp is helpful in organizing, storing, retrieving, and finding the information related to the experiments. Time stamp is taken from the table to extract the month and day in which the reading is being taken. Month and day are converted into a number ranging from 0-365 days in a year using a function. Based on this converted value, it is mapped to an address 20568 in the "reference" table. In this table, 71 is the value stored in the "day" field and 2045 is an address points to a linked list collection of Binary Search Tree (BST). To store the reading of an experiment, a node is created in the linked list with a value "1606979426043" for "timestamp", 1092 for pointer to address of BST and 2074 pointer of the next node in the linked list. This linked list will be a sorted list, consisting of entries of all experiments carried on a 
particular day. To insert a value in the linked list, the entire list will be searched and will be inserted in the respective place.

BST is utilized to store the reading of the experiments. It is a continuation of binary tree and provides an efficient way of organizing the elements for storing, retrieving and finding. Accessing an element in BST takes a time complexity of $\mathrm{O}(\log 2(\mathrm{n}))$ then a linear search with $\mathrm{O}(\mathrm{n})$. So, it otherwise calls as logarithmic search. To convert the tree into searchable, the elements in the tree must be comparable and understand the relationship between the elements. To establish this condition, each element must exhibit a Total Order relationship property. When two elements are compared with each other, there exists a property called comparable. This Comparator exhibits the following set of rules:

1) Reflexive Relation - If every element in the set map to itself in the set. A relation is reflexive if: $(a, a) \in \mathrm{R} \forall \mathrm{a} \in \mathrm{A}$, where $\mathrm{R}$ is the relation, $\mathrm{A}$ is the set and $\mathrm{a}$ is the element in the set.

2) Anti-Symmetric Relation - Relation $R$ of a set $A$ is anti-symmetric if $(a, b) \in R$ and (b, a) $\in$ $\mathrm{R}$, then $\mathrm{a}=\mathrm{b}$.

3) Transitive Relation - If (a, b) $\in \mathrm{R}$ and ( $b, c) \in \mathrm{R}$, then (a, c) also belongs to R, where a, b, c is the element in the set and $\mathrm{R}$ is the relation.

4) Comparable Relation - For any $\mathrm{a}, \mathrm{b}$, in the set, either $a \leq \mathrm{b}$ (or) $\mathrm{b} \leq \mathrm{a}$.

BST is a special tree which contains an order way of arranging the nodes in Fig. 3a. The elements on the left side of the parent are lesser and the elements on the right side of the parent are greater. A node is represented by two values as "feature" and "temp" as feature and temperature, with two pointers as "left" and "right" as the left child and right child. Feature and temperature values correspond to feature used in measurement used in the experiment and its temperature respectively, while pointer stores the address of its child's. The size of the "feature" and "temp" value is 15 bytes of character and 4 bytes of integer respectively. Both the pointers are of 4 bytes of integer. The first node in the binary search tree is identified by a pointer named as root.

\section{Insertion:}

\section{Step 1:}

When inserting a node "solar radiation" and 779 as temperature in BST is shown in Fig. 3b(i), it checks for the Root pointer. Since the Root pointer is NULL initially. It creates a new node and 
changes the Root value to point to the address of the newly created node. Here, the newly created node address value is 9000 and it is stored in the Root pointer.

\section{Step 2:}

Inserting of the second node in BST needs to compare the root node with the value to be inserted in Fig. 3b(ii). From the comparison, new value is smaller than the root node value in terms of the alphabet comparison. Again, the comparison must be continued on the left side of the root. Since, the left child of the root node is NULL. A new node is created and it is inserted at the left child of the first node. The left child of the root node is assigned a value of 3120 which is the address of the newly created node.

\section{Step 3:}

The node to be inserted in BST takes a value "glass cover" and " 44.31 " for "feature" and "temp" fields. This "glass cover" is compared with the root node and the right child of root node. It is smaller than root and greater than "ambient" node, so a new node is created and its address is assigned to the right child pointer of it is 9190 . Fig. $3 b$ (iii) shows in the below diagram.

\section{Step 4:}

The new node is inserted at the right child of "glass cover" with an address value of 9070. Before insertion it is compared with "solar radiation", "ambient" and "glass cover" node. During comparison it is found that the value is less than "solar radiation", while it is greater than "ambient" and "glass cover" node. So, it is inserted to right of "glass cover" node in Fig. 3b(iv).

\section{Step 5:}

The new node with a value of "basin" as "feature" and "64.3" as "temp" is inserted to the left child of "glass cover" with an address value of 9340. Before insertion it is compared with "solar radiation", "ambient" and "glass cover" node in Fig. 3b(v). During comparison it is found that the value is smaller than "solar radiation", while it is greater than "ambient" node. So, it is compared with "glass cover" node and inserted to the left after comparison.

\section{Step 6:}

The new node with a value of "water" as "feature" and "61.3" as "temp" is inserted to the right child of "solar radiation" with an address value of 9030 in Fig. 3b(vi).

\subsection{Simulation models of solar still results}


BST followed an insertion diagram have analyzed the temperature of the values as ways of OSELM control stability for SBSS. The performance of the solar still has evaluated in order of the model estimation and checked to the validity of the control energy operating parameters discussed and evaluations of the system.

The simulation model verified the origin Pro2020 version, and Microsoft Windows service 2010 $\mathrm{R}^{2}$ arrived value an atmosphere and occupied in $\mathrm{CO}$ concentration. The evaluation of the system has been standard to an analysis of an integral of Absolute Error (IAE), Integral of Square Error (ISE) and maximal Deviation from the setpoint ( $\mathrm{D}^{\mathrm{max}}$ ).

$$
\begin{aligned}
& \mathrm{IAE}=\int_{t o}^{t 1}|R(t)-Y(t)| \cdot d t \\
& \mathrm{ISE}=\int_{t o}^{t 1}(R(t)-Y(t))^{2} \cdot d t \\
& \left(\mathrm{D}^{\max }\right)=\max |R(t)-Y(t)|
\end{aligned}
$$

where $\mathrm{R}(\mathrm{t}), \mathrm{Y}(\mathrm{t})$ have referred by solar still Input, output and IAE designates the transient response. ISE is suitable damping, $\left(\mathrm{D}^{\max }\right)$ indicates control for solar stability evaporation process as by Hong et al., [31] and Guang et al., [32].

$$
\begin{aligned}
& \lim _{k \rightarrow \infty} \sigma_{k}\left[\frac{e_{k+1}^{* 2}}{\left(1+\sigma_{k} \Phi_{k} P_{k-1} \Phi_{k}^{T}\right)^{2}}-\varepsilon^{2}\right] \times \mathrm{Q}_{\text {total energy }+N} m_{w}=0 \\
& \lim _{k \rightarrow \infty} \operatorname{sub} \frac{e_{k+1}^{* 2}}{\left(1+\sigma_{k} \Phi_{k} P_{k-1} \Phi_{k}^{T}\right)^{2}} \leq \varepsilon^{2} \times \mathrm{Q}_{\text {total energy }+N} m_{w}
\end{aligned}
$$

The comparison of online learning algorithms is investigated in SBSS through the heat transfer to verify all parameters the inherent characteristic of the OSELM such as SVR, Go-GP GOD-LR, respectively. The large-scale data were not considering handle for Go GP and adapted precisely with streaming data. These online learning methods have compared that solar still parameter values, yield of the water data produced by the BSM1 model and controlled through evasion PI organizer. 1450 groups, 1000 groups are the total number of set data and collected by SBSS data for fast productive ways. From table 1 are the solar still parameters of OSRLM and the fastest working process is online SVR. From table 1, the training time of OSELM is the fastest among these plans, especially for Online SVR. OSELM is still the lowest Root Mean Square (RMSE) compared with other methods. As applied in table 1 for the solar still temperature analysis of OSELM is high-speed methods, especially for online SVR. The lower root means square error (RMSE) opposed to the process. Also, $\mathrm{R}^{2}$ the online process of GOGP is greater than SRV. The 
SBSS concluded that the process of OSELN is a very good performance of machine learning methods and its application of learning methods.

\subsection{The analysis of SBSS with uncertainty and error}

The error and uncertainty analysis of SBSS occurs with an outcome of the measurement technique. A piece of equipment and the instrument provider collect different quantities was the majority information of the SBSS. The experiments based on outcomes were defected to arising to develop techniques by Taylor (1997). The temperature absorption of the parameters to variations of directly was measured by the SBSS. The freshwater harvest is observed by the natural ways to give in systemic sources of errors. The uncertainty $\delta$ of value $\mathrm{S}$ has calculated the efficiency of SBSS as the following formula by Taylor, 1997 (32 q); Holman, 2011(33w); Hassan et al. 2020a (34b); Rashidi et al. (2018 - 34c). The experimental observe values development with conservation environments, calibration, then the error of measurement devices. The experimental values an error with devices have been characterized as

$$
\delta_{S B S S}=\sqrt{\left(\frac{\partial S}{\partial X}\right)^{2} \delta_{X}^{2}+\left(\frac{\partial S}{\partial Y}\right)^{2} \delta_{Y}^{2}}
$$

where $\delta_{\mathrm{i}}$ and $\delta_{\mathrm{ii}}$ are the uncertainty of measured values $\mathrm{X}$ and $\mathrm{Y}$, respectively, and more than two recorded values can be added to this equation. For example, energy efficiency uncertainty is calculated to be $1.9 \%$. The instruments and device's measuring data to use on the SBSS have shown that uncertainty values estimate Table 2. The energy efficiency of the SBSS has been used in uncertainty as followed by the equation (18) and (10), which was measured by the values of solar intensity and harvested with freshwater by the system. At that period of the SBSS was studied to calibrate all measurement sensors (thermocouples, flasks, etc.) and instruments (voltmeter, ohmmeter, etc.). It is also showed that the properties of the calibration consequences designated in this investigation were observed.

\section{Results and discussion}

The weather conditions analysis of the SBSS has fixed in KLEF at solar energy laboratory in latitude $-16.5062^{\circ} \mathrm{N}$, longitude $-80.6480^{\circ} \mathrm{E}$. The parameters performance is used in variety volume fractions $(10 \%, 20 \%, 30 \%, 40 \%, 50 \%)$ by the SBSS, which measured an effect of temperature like ambient, glass, moist air, stepped basin, saline water, and solar radiation. It was experimentally verified for every 30 mints as shown in Fig. 4 (a to e). The parallel an 
experimentally of the systems have analyzed solar radiation, then ambient temperature. It calculated solar intensity and ambient temperature. The maximum during the peak was higher up to $3.00 \mathrm{pm}$ and abridged through the nightfall reduced the system. The SBSS have verified exploitation of $20 \%$ and $30 \%$ furious $\mathrm{SiO}_{2} / \mathrm{TiO}_{2}$ nanolayer enhanced an average the temperature increases of $21.9 \%$ and $29.7 \%$ in Figs. 5. Which has compared to that of the systems with nanolayer coated by the stepped basin of energy absorption for single furious $\mathrm{SiO}_{2}, \mathrm{TiO}_{2}$, and without $\mathrm{SiO}_{2} / \mathrm{TiO}_{2}$. The temperature achieved by the SBSS were various ratio of $10 \%, 20 \%, 30 \%, 40 \%, 50 \%$ nanofluids that used a basin absorption is 58.4,63.4, 64.7, 63.2,63.0 $\pm 0.1^{\circ} \mathrm{C}$, and stepped basin area have 58.4,62.6, 64.5, 61.5,62.2 ${ }^{\circ} \mathrm{C}$ by Abdullah et al., [33] respectively. The fuming $\mathrm{SiO}_{2} / \mathrm{TiO}_{2}$ nanolayer is coated by the internal heat transfer modes to contact the basin, stepped basin, moist air, water temperature that concurrently improved for heat energy functions. $20 \%, 30 \%$ for furious on $\mathrm{SiO}_{2} / \mathrm{TiO}_{2}$ nanolayer used in SBSS has achieved a temperature of $63.4,64.7 \pm 0.1^{\circ} \mathrm{C}$ and compared to higher than as 40\%,50\% respectively, Rashidi et al. [34].

Since, the glass, water temperature using $40 \%, 50 \%$ are higher, it is $9.14,13.14 \%$ and $8.14,11.46 \%$ respectively, which are higher than solar still with single elements, without nanolayer. Fig. 4 (a to e) focused on hourly variations in the characteristic of the SBSS with mechanisms of the temperature range in glass, basin, steeped basin, moist air, water, and ambient temperature. An experimental conducted to different a ratio used for furious $\mathrm{SiO}_{2} / \mathrm{TiO}_{2}$ nanolayer have observed that the typical ambient temperature to analysis in parallel systems. The different rate of $10 \%, 20 \%, 30 \%, 40 \%, 50 \%$ of the furious $\mathrm{SiO}_{2} / \mathrm{TiO}_{2}$ nanolayer occupied average basin temperature of the system. It concluded that of as 58.3, 61.6, 64.5, 59.9 and $59.1 \pm 0.1^{\circ} \mathrm{C}$ individually. Therefore, the thermal conductivity focusses on the furious $\mathrm{SiO}_{2} / \mathrm{TiO}_{2}$ nanolayer increased with a ratio of $20 \%, 30 \%$, and reduced by the rate of $40 \%, 50 \%$ in basin temperature. It is used the mixed nanolayer with temperature in basin area gain with heat energy of the SBSS is increased by $10.34 \%, 15.17 \%$, and the ratio of $20 \%, 30 \%$. The performance of the SBSS has enhanced for evaporation to an essential role of absorption with the saline water. The average temperature produced in the basin temperature an increase of $9.42 \%$ and $14.23 \%$ respectively. A stepped basin temperature, as achieved by the SBSS has been raised by virtually $71^{\circ} \mathrm{C}$ period for working hours by Shanmugan et al., [34] and Essa et al., [35] as followed by Fig.4(c). 
Fig. 5 is shown in hourly variations to improve the average temperature for the SBSS have produced by the hourly variations with a maximum temperature of enhanced single elements, without nanoparticles $0.73,0.77 \pm 0.01 \mathrm{~kg} / \mathrm{m}^{2}$, which coated of SBSS with $10,20,30,40,50 \%$ the

furious $\mathrm{SiO}_{2} / \mathrm{TiO}_{2}$ nanolayer have achieved of $0.74,0.76,0.78,0.77$ then $0.76 \pm 0.01 \mathrm{~kg} / \mathrm{m}^{2}$ respectively and achieved with highest solar radiation at 11.00 to 15.00 by Rashidi et al. (36 and 37).

The production of the SBSS has been attained through the daylight 60 minutes since 8.00 am to 06:00 pm. Fig. 6 is the amount of distillate yield of the proposed still in typical days in June 2019 to June 2020. The SSBC be used in $12 \mathrm{~kg}$ water in a method of the temperature virtually $30 \mathrm{~min}$. $\mathrm{SiO}_{2} / \mathrm{TiO}_{2}$, single $\mathrm{SiO}_{2}, \mathrm{TiO}_{2}$, without nanoparticles has been produced yield increases in the forenoon as reached in the maximum distillate of $0.467,0.430,0.379,0.221 \mathrm{~mL}$ respectively since 11.30 to 15.00. Simulation model SBSS was shown Fig.6 as a nanocoating on the stepped basin surface, which is improved in the yield of fresh water throughout the days. It has been observed that in total daily distillate yield over the 24-hour cycle is deemed to be $8.11,6.19,5.89,3.73 \mathrm{~L} /$ day, respectively. 20\%, 30\% ratio used in SBSS has increased the average heat energy daily performance of $21.5 \%, 24.6 \%$ as higher and compared to single elements, without nanolayer. Similarly, SBSS coated in a stepped basin with higher temperature achieved for use by $40 \%, 50 \%$ and without nanolayer concluded stepped basin in peak time a sunlight period.

The Fig. 7(a) as followed with a performance of the SBSS with a ratio of $10 \%, 20 \%, 30 \%, 40 \%, 50 \%$ $\mathrm{SiO}_{2} / \mathrm{TiO}_{2}$ nanolayer have achieved by a system of $31.77 \%, 37.69 \%, 49.21 \%, 36.99 \%$ and $34.66 \%$. To compare the single elements, without nanolayer coated, harvests the stepped basin responses. The SBSS has achieved in a simulation that the course of the ambient, glass cover, basin saline water, solar radiation and distillate production throughout the year. It is achieved that nanoparticles of with, Single, without nanolayer have coated by a stepped basin area improvement of yield production by SBSS as showed in Fig.7(b). It found that to be overall efficiency of $61.14 \%$ as a $\mathrm{SiO}_{2} / \mathrm{TiO}_{2}$ nanolayer (30\%) is achieved by Shanmugan et al., [34] and Essa et al., [35].

\subsection{The SBSS Strategies with evaluation for Energy control}

SBSS has included as BSM influent load data for the temperature analysis of the initialization condition of the system. The analysis of the solar still was important one-year simulation data of 
0.0001. The SBSS control simulation model is selected as an initialization data use of OSELM founded adaptive controller on the BSM model. Performance of the SBSS controlled weather conditions, as showing in Figs. $8 \mathrm{a} \& 8 \mathrm{~b}$. It controlled for weather condition for the variable an algorithm as good performance of the SBSS. The error analysis of the solar still controlled flexible set point range of $\pm 0.05 \mathrm{mg} /$ day frequently.

A comparison of the SBSS with further controller approaches in weather conditions as followed in Table 3. SBSS is supervised by the IAE, ISE and D max, which have calculated for 0.0564, $0.0057,0.0472$ and better values of the system. The regular performance of the SBSS was evaluated to compare an establishes a fast-moving transient with a response to appropriates of damping. It used the heat transfers excessive permanency of the SBSS individually.

\section{Conclusion}

SBSS was used as a nonlinear composite design based on a neural network with a controller in an approach that has been analyzed of heat transfer usually. Though nearly scarcities with a traditional neural network affect a consultation innovative control responsibilities also huge period feasting. The SBSS has been achieved a good control effect of research for OSELM based adaptive control with the recursive least square method was introduced for thermal application one of the solar still design. The neural network-based to control approach the evaporation process and solar design for

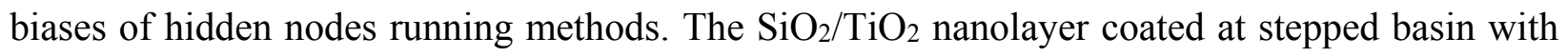
the effect of different ratio used a solar still have been enhanced high temperature, which is increased an evaporation process. SBSS is the foremost important to handle influence the stepped basin and enhanced to that of heat transfer modes. The $\mathrm{SiO}_{2} / \mathrm{TiO}_{2}$ nanoparticles average temperature were the glass, water, stepped basin, moist air, which enhanced of $12.5 \%, 16.4 \%$, $16.5 \%, 16.3 \%$ individually through about 30\%. The SBSS stepped basin increases the absorption ratio mixture nanoparticle by the $30 \%$, stepped basin temperature, which is no signification for nanoparticle development of the parameters. From furious $\mathrm{SiO}_{2} / \mathrm{TiO}_{2}$ nanoparticles of the SBSS efficiency were increased by $37.69 \%$ and $49.21 \%$ using $20 \%$ and $30 \%$. The overall efficiency $30 \%$ in the SBSS is $61.14 \%$. It is higher as per equated to that of $\mathrm{SBSS}$ with analysis of $\mathrm{SiO}_{2}, \mathrm{TiO}_{2}$, without nanoparticles for the systems. The BSTs have studied algorithms to improve a higher bound by a price with a product and the central part of BST authorizations originate a limit of the 
cost optimum of the solar still and developed with previous significances. Time-stamped storage and retrieval of temperature in the memory gives an authenticated way of accessing the correct data in our experiment.

\section{Acknowledgement:}

I would say thanks a lot to Department of Science and Technology (DST, Delhi), Government of India for the award of DST-FIRST Level-1(SR/FST/PS-1/2018/35) scheme to the Department of Physics. Appreciations are grateful to the KLEF offering infrastructure, facilities, basic found (Perform basic instruments) and support to the current investigation.

\section{NOMENCLATURE}

Aeff - $\quad$ Effective area of the stepped basin surface $\left(\mathrm{m}^{2}\right)$

$A_{c} \quad-\quad$ stepped basin surface of the SBSS $\left(\mathrm{m}^{2}\right)$

$\mathrm{C}_{\mathrm{w}} \quad-\quad$ Capacity of heat transfer to water (L)

$\mathrm{E}_{\mathrm{o}-N} \quad-\quad$ nanolayer occupied the internal energy $(\mathrm{kJ})$

lg $\quad$ - $\quad$ Length of the glass cover $\left(\mathrm{m}^{2}\right)$

$b_{g} \quad-\quad$ Breadth of the glass cover $\left(\mathrm{m}^{2}\right)$

$\mathrm{h}_{\mathrm{cwg}} \quad$ - Convective heat transfer coefficient from stepped basin to glass cover $\left(\mathrm{W} / \mathrm{m}^{2} \mathrm{~K}\right)$

hewg - $\quad$ Evaporative heat transfer coefficient from stepped basin to glass cover $\left(\mathrm{W} / \mathrm{m}^{2} \mathrm{~K}\right)$

$\mathrm{h}_{\mathrm{rwg}} \quad$ - $\quad$ Radiative heat transfer coefficient from stepped basin to glass cover $\left(\mathrm{W} / \mathrm{m}^{2} \mathrm{~K}\right)$

$\mathrm{h}_{\mathrm{L}} \quad-\quad$ Convection heat transfer coefficient loss of the SBSS $\left(\mathrm{W} / \mathrm{m}^{2} \mathrm{~K}\right)$

$\mathrm{P}_{\mathrm{w}} \quad$ - $\quad$ Saturated vapor pressure at water temperature $\left(\mathrm{Nm}^{-2}\right)$

$\mathrm{P}_{\mathrm{g}} \quad-\quad$ Saturated vapor pressure at glass temperature $\left(\mathrm{Nm}^{-2}\right)$

$\mathrm{Q}_{\text {total energy }+N^{-}} \quad$ amount of total energy $\left(\mathrm{W} / \mathrm{m}^{2}\right)$

$\dot{\mathrm{Q}}_{\mathrm{ep}} \quad$ - Total heat transfer an evaporation power $\left(\mathrm{W} / \mathrm{m}^{2}\right)$

$\mathrm{T}_{\mathrm{w}} \quad-\quad$ Temperature of the water surface $(\mathrm{K})$

$\mathrm{T}_{\mathrm{wo}} \quad-\quad$ Initial temperature of the stepped basin water surface (K) 


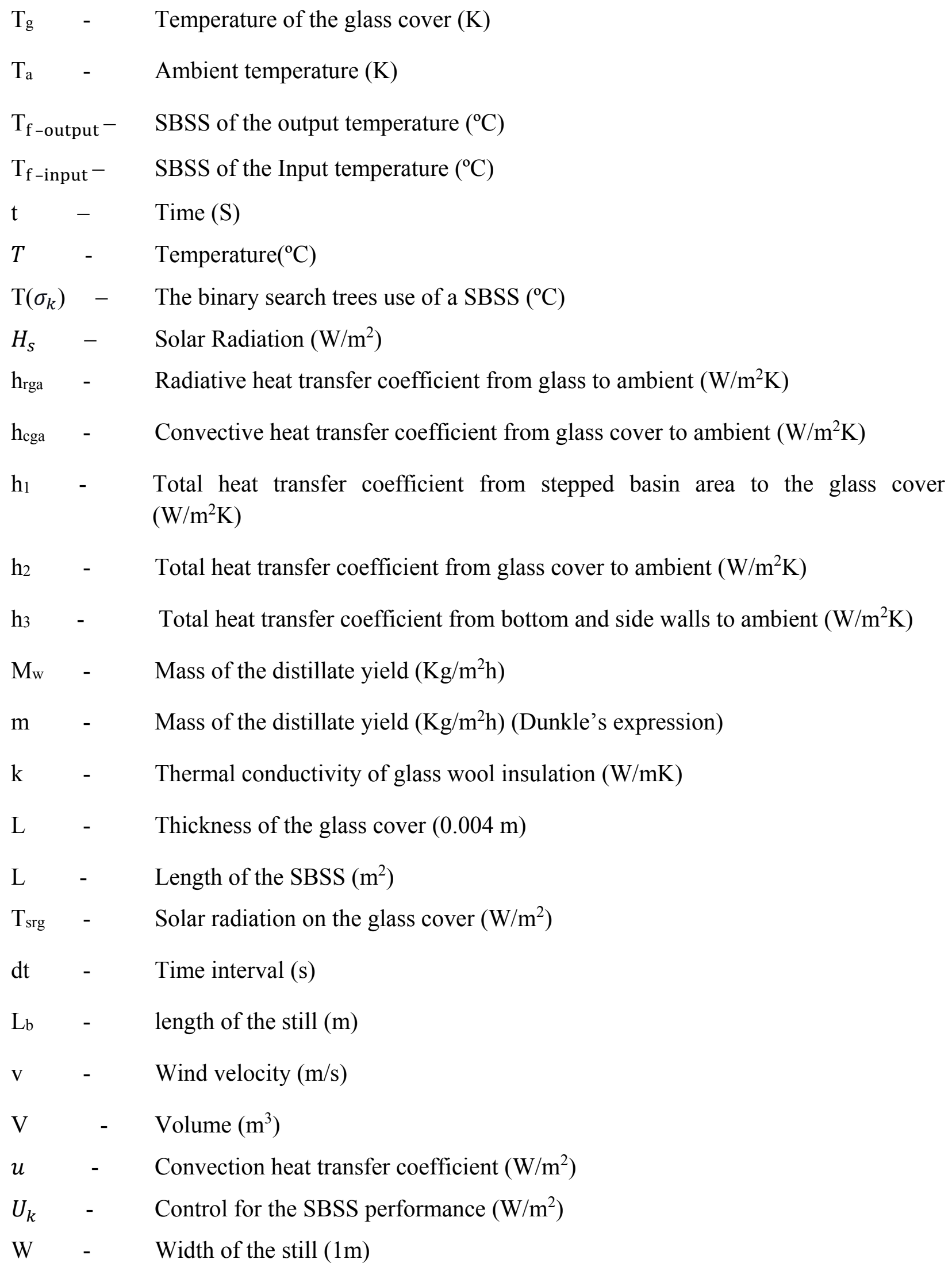


IAE - $\quad$ standard to an analysis of an integral of Absolute Error $\left({ }^{\circ} \mathrm{C}\right)$

ISE - - Integral of Square Error $\left({ }^{\circ} \mathrm{C}\right)$

$\mathrm{D}^{\max } \quad-\quad$ maximal Deviation from the setpoint $\left({ }^{\circ} \mathrm{C}\right)$

$\mathrm{R}(\mathrm{t}), \mathrm{Y}(\mathrm{t})$ - $\quad$ referred by SBSS Input, output $\left({ }^{\circ} \mathrm{C}\right)$

$\mathrm{S} \quad$ - $\quad$ The calculated the efficiency of SBSS

SBSS - $\quad$ Stepped Basin Solar Still

\section{Greek symbols}

$\varepsilon \quad-\quad$ Emissivity of the water surface.

$\sigma \quad$ - $\quad$ Stefen-Boltzman constant. $\left(\mathrm{W} / \mathrm{m}^{2} \mathrm{~K}^{4}\right)$

$\sigma_{1}$ of $\sigma_{k}-\quad$ glass cover, stepped basin, moist air, water temperature, distillate output $\left({ }^{\circ} \mathrm{C}\right)$

$\eta \quad$ - Instantaneous Thermal efficiency of the still

$\eta_{\text {total energy }+N}-\quad$ Overall thermal efficiency by the SBSS (\%)

$\tau_{\mathrm{g}} \quad$ - $\quad$ Transmissivity of glass cover

$\alpha_{\mathrm{g}} \quad$ - $\quad$ Absorptivity of the glass cover

$\alpha_{\mathrm{w}} \quad$ - $\quad$ Absorptivity of the stepped basin surface

$\delta \quad$ - $\quad$ The uncertainty values of SBSS

$\Phi \quad$ - $\quad$ Pseudo-inverse based on back point $\left({ }^{\circ} \mathrm{C}\right)$

$\omega_{i}, m_{i}$, and $\theta_{i},-\quad$ SBSS as zero error with existing for evaporation $\left({ }^{\circ} \mathrm{C}\right)$

\section{References}

1. B. Perez-Sanchez, O. Fontenla-Romero, B. Guijarro-Berdinas, D. Mart'inez-Rego, An online learning algorithm for adaptable topologies of neural networks, Expert Systems with Application, 40(18), 7294-7304, 2013. https://doi.org/10.1016/j.eswa.2013.06.066. 
2. J. Qiao, Z. Zhang, Y. Bo, An online self-adaptive modular neural network for time-varying systems, Neuro computing, 125, 7-16, 2014. DOI: 10.1016/j.neucom.2012.09.038Corpus ID: 42817195.

3. E. Lughofer, on-line active learning: A new paradigm to improve practical use ability of data stream modeling methods, Information Sciences, 415(416), 356-376, 2017. https://doi.org/10.1016/j.ins.2017.06.038.

4. Q. Zhang, P. Zhang, G. Long, W. Ding, C. Zhang, X. Wu, Online learning from trapezoidal data streams, IEEE Transactions on Knowledge and Data Engineering, 28(10), 2709-2723, 2016. DOI: 10.1109/TKDE.2016.2563424.

5. Z. Zhou, W.S. Zheng, J.F. Hu, Y. Xu, J. You, One-pass online learning: A local approach, Pattern Recognition, 51, 346-357, 2016. https://doi.org/10.1016/j.patcog.2015.09.003.

6. C. Suresh, S. Shanmugan, Effect of water flow in a solar still using novel materials, J Therm. Anal. Calorim., 2019. https://doi.org/10.1007/s10973-019-08449-5.

7. P. Zanganeh, A. S. Goharrizi. S. Ayatollahi, M. Feilizadeh, Productivity enhancement of solar stills by nano-coating of condensing surface, Desalination, 54, 1-9, 2019. https://doi.org/10.1016/j.desal.2018.12.007

8. C. Suresh, S. Shanmugan, M.V. Bharath, B. Naveen, V. Chithambaram, Experimental analysis of Energy and Environment redeemable in solar Nano-basin still to improve Sullage Water Natural Treatment of Fuzzy Application, Materials Today: Proceedings, 18(3), 12631271, 2019. https://doi.org/10.1016/j.matpr.2019.06.588.

9. P. Zanganeh, A. S. Goharrizi, S.Ayatollahi, M. Feilizadeh, Nano-coated condensation surfaces enhanced the productivity of the single-slope solar still by changing the condensation mechanism, Journal of Cleaner Production, 265, 121758, 2020. https://doi.org/10.1016/j.jclepro.2020.121758.

10. A.S. Abdullah, F.A. Essa, H.B. Bacha, Z.M. Omara, Improving the trays solar still performance using reflectors and phase change material with nanoparticles, Journal of Energy Storage, 31, 101744, 2020. https://doi.org/10.1016/j.est.2020.101744.

11. P. Zanganeh, A.S. Goharrizi, S. Ayatollahi, M. Feilizadeh, H. Dashti, Efficiency improvement of solar stills through wettability alteration of the condensation surface: An experimental study, Applied Energy, 268, 114923, 2020. 
https://doi.org/10.1016/j.apenergy.2020.114923.

12. S. Shanmugan, S. Palani, B. Janarthanan, Productivity enhancement of solar still by PCM and Nanoparticles miscellaneous basin absorbing materials, Desalination, 433, 186-198, 2018. https://doi.org/10.1016/j.desal.2017.11.045.

13. A. Agrawal, R.S. Rana, P.K. Srivastav, Heat transfer coefficients and productivity of a single slope single basin solar still in Indian climatic condition: Experimental and theoretical comparison, Resource-Efficient Technologies, 3(4), 466-482, 2017. https://doi.org/10.1016/j.reffit.2017.05.003.

14. T. Arunkumar, D. Murugesan, K. Raj, D. Denkenberger, C.Viswanathan, D.D.W. Rufuss, R.Velraj, Effect of nano-coated $\mathrm{CuO}$ absorbers with PVA sponges in solar water desalting system, Applied Thermal Engineering, 148, 1416-1424, 2019. https://doi.org/10.1016/j.applthermaleng.2018.10.129.

15. S.M. Saleh, A.M. Soliman, M.A. Sharaf, V. Kale, B. Gadgil, Influence of solvent in the synthesis of nano-structured $\mathrm{ZnO}$ by hydrothermal method and their application in solar-still, Journal of Environmental Chemical Engineering, 5(1), 1219-1226, 2017. https://doi.org/10.1016/j.jece.2017.02.004

16. A. Mahmoud, H. Fath, S. Okpara, M. Ahmed, Influence of partial solar energy storage and solar concentration ratio on the productivity of integrated solar still/humidificationdehumidification desalination systems, Desalination, 467, 29-42, 2019. https://doi.org/10.1016/j.desal.2019.04.033.

17. W. Wang, X. Huan, C. Wang, Thermal annealing characteristics of solar selective absorber coatings based on nano-multilayered MoOx films, Ceramics International, Available online article presses 24 July 2020. https://doi.org/10.1016/j.ceramint.2020.07.205.

18. Isabel Santacruz, Aurelio Cabeza, PaulIbeh, Enrique R. Losilla, Angeles G. De la Torre, Miguel, A.G. Aranda, Preparation of photocatalytic $\mathrm{TiO}_{2}$ coatings by gel-dipping with polysaccharides, Ceramics International, 38(8), 6531-6540, 2012. https://doi.org/10.1016/j.ceramint.2012.05.034.

19. Hualong Liu, Wang Guo, Yarong Li, Shasha He, Chiyang He, Photocatalytic degradation of sixteen organic dyes by $\mathrm{TiO}_{2} / \mathrm{WO}_{3}$-coated magnetic nanoparticles under simulated visible 
light and solar light, Journal of Environmental Chemical Engineering, 6(1), 59-67, 2018. https://doi.org/10.1016/j.jece.2017.11.063.

20. S.W. Sharshir, G. Peng, A.H. Elsheikh, E.M.A. Edreis, M.A. Eltawil, T. Abdelhamid, A.E. Kabeel, J. Zang, N. Yang, Energy and exergy analysis of solar stills with micro/nano particles: A comparative study, Energy Conversion and Management, 177, 363-375, 2018. https://doi.org/10.1016/j.enconman.2018.09.074.

S. Rashidi, N. Karimi, O. Mahian, J. A. Esfahani, A concise review on the role of nanoparticles upon the productivity of solar desalination systems. Journal of Thermal Analysis and Calorimetry, 135, 1145-1159, 2019. https://doi.org/10.1007/s10973-018-7500-8.

S. Rashidi, S. Akar, M. Bovand, R. Ellahi, Volume of fluid model to simulate the nanofluid flow and entropy generation in a single slope solar still. Renewable Energy, 115, 400-410 2018. https://doi.org/10.1016/j.renene.2017.08.059.

S. Rashidi, M. Bovand, N. Rahbar, J. A. Esfahani, Steps optimization and productivity enhancement in a nanofluid cascade solar still. Renewable Energy 118, 536-545 (2018). https://doi.org/10.1016/j.renene.2017.11.048.

S. Rashidi, N. Rahbar, M. S. Valipour, J.A. Esfahani, Enhancement of solar still by reticular porous media: Experimental investigation with exergy and economic analysis. Applied Thermal Engineering 130, 1341-1348, (2018). https://doi.org/10.1016/j.applthermaleng.2017.11.089.

21. M. Feilizadeh, M. Soltanieh, M.R.K. Estahbanati, K. Jafarpur, S.S. Ashrafmansouri, Optimization of geometrical dimensions of single-slope basin-type solar stills, Desalination, 424, 159-168, 2017. https://doi.org/10.1016/j.desal.2017.08.005.

22. A. Salarabadi and M. Rahimi, Experimental investigation of using an evaporation inhibitor layer in a solar still, Solar Energy, 206, 962-973, 2020. https://doi.org/10.1016/j.solener.2020.06.076. 
N. Rahbar, A. Gharaiian, S. Rashidi, Exergy and economic analysis for a double slope solar still equipped by thermoelectric heating modules - an experimental investigation, Desalination, 420, 106-113, 2017. https://doi.org/10.1016/j.desal.2017.07.005.

23. N.Y. Liang, G.B. Huang, P. Saratchandran, P. Sundarajan, Fast and accurate online sequential learning algorithm for feedforward networks, IEEE Trans. Neural NetW., 17(6), 1411-1423, 2006. DOI: 10.1109/TNN.2006.880583.

24. Guang-Bin Huang, Qin-Yu Zhu, Chee-Kheong Siew, Extreme learning machine: Theory and $\begin{array}{llll}\text { applications, } & \text { Neurocomputing, } & \text { 70(1-3), } & \text { 489-501, }\end{array}$ https://doi.org/10.1016/j.neucom.2005.12.126.

25. V. Alfred, Aho, E. John, Hopcroft, D. Jeffrey, Ullman, Data Structures and Algorithms, Addison-Wesley, 1983.

26. E. Donald, Knuth. Sorting and Searching, 2nd edition, in: The Art of Computer Programming, 3, Addison-Wesley, 1998.

27. T. H. Cormen, C. E. Leiserson, R. L. Rivest, Clifford Stein, Introduction to Algorithms, 2nd edition, MIT Press, 2001.

28. Roberto De Prisco, On binary search trees Information Processing, Letters, 45, 219-293, 1993. https://doi.org/10.1016/0020-0190(93)90212-R.

29. Navin Goyal, Manoj Gupta, Better analysis of Greedy binary search tree on decomposable Sequences, Theoretical Computer Science, 776, 19-42, 2019. https://doi.org/10.1016/j.tcs.2018.12.021.

30. Bodo Mantheya, Rudiger Reischuk, Smoothed analysis of binary search trees, Theoretical Computer Science, 378, 292-315, 2007. https://doi.org/10.1016/j.tcs.2007.02.035

31. Hong-Gui Han, Senior Member, Lu Zhang, Ying Hou, and Jun-Fei Qiao, Nonlinear Model Predictive Control Based on a Self-Organizing Recurrent Neural Network, IEEE transactions on neural networks and learning systems, 27(2), 2465174, 2016. DOI: 10.1109/TNNLS.2015.2465174. 
32. Guang-Bin, Huang Qin-Yu, Zhu Chee-Kheong. Extreme learning machine: Theory and $\begin{array}{llll}\text { applications, } & \text { Neurocomputing, } & \text { 70(1-3), } & \text { 489-501, }\end{array}$ https://doi.org/10.1016/j.neucom.2005.12.126.

(32q) J.R. Taylor, 1997. An Introduction to Error Analysis: The Study of Uncertainties in Physical Measurements. University Science Books.

(33w) J.P. Holman, 2011. Experimental Methods for Engineers. McGraw-Hill.

(34b) H. Hassan, M. S. Ahmed, M. Fathy, M.S. Yousef, Impact of salty water medium and condenser on the performance of single acting solar still incorporated with parabolic trough collector Impact of salty water medium and condenser on the performance of single acting solar still incorporated with parabolic trough collector, Desalination, 480, 114324, 2020. https://doi.org/10.1016/j.desal.2020.114324.

S. Rashidi, M. Bovand, J. A. Esfahani, Volume-of-Fluid Model for Simulating Vapor-Liquid Phase Change in a Solar Still, Journal of Thermophysics and Heat Transfer, 32, 917-924, 2018. http://arc.aiaa.org | DOI: 10.2514/1. T5316.

33. A.S. Abdullah, M.M. Younes, Z.M. Omara, F.A. Essa, New design of trays solar still with enhanced evaporation methods - Comprehensive study, Solar Energy, 203, 164-174, 2020. https://doi.org/10.1016/j.solener.2020.04.039.

34. S. Shanmugan, F.A. Essa, Shiva Gorjian, A.E. Kabeel, R. Sathyamurthy, A.M. Manokar, Experimental study on single slope single basin solar still using $\mathrm{TiO}_{2}$ nano layer for natural clean water invention, Journal of Energy Storage, 30, 101522, 2020. https://doi.org/10.1016/j.est.2020.101522.

35. F.A. Essa, A.H. Elsheikh, R. Sathyamurthy, A.M. Manokar, A.W. Kandeal, S. Shanmugan, A.E. Kabeel, S.W. Sharshir, H. Panchal, M.M. Younes, Extracting water content from the ambient air in a double-slope half-cylindrical basin solar still using silica gel under Egyptian 
conditions, Sustainable Energy Technologies and Assessments, 39, 100712, 2020. https://doi.org/10.1016/j.seta.2020.100712.

S. Rashidi, J. A. Esfahani, N. Rahbar, Partitioning of solar still for performance recovery: Experimental and numerical investigations with cost analysis. Solar Energy, 153, 41-50, 2017. https://doi.org/10.1016/j.solener.2017.05.041.

S. Rashidi, M. Bovand, J. A. Esfahani, Optimization of partitioning inside a single slope solar still for performance improvement, Desalination, 395, 79-91, 2016. https://doi.org/10.1016/j.desal.2016.05.026.

36. Hong-Gui Han, Jun-Fei Qiao, Qi-Li Chen, Model predictive control of dissolved oxygen concentration based on a self-organizing RBF neural network, Control Engineering Practice, 20(4), 465-476, 2012. https://doi.org/10.1016/j.conengprac.2012.01.001.

37. B. Holenda, E. Domokos, A. Redey, J. Fazakas, Dissolved oxygen control of the activated sludge wastewater treatment process using model predictive contro, Computers \& Chemical Engineering, 32(6), 1270-1278, 2008. https://doi.org/10.1016/j.compchemeng.2007.06.008.

38. Carlos Alberto, Coelho Belchior, Rui Alexandre, Matos Araujo, Jorge Afonso Cardoso Landeck. Dissolved oxygen control of the activated sludge wastewater treatment process using stable adaptive fuzzy control, Computers \& Chemical Engineering, 37(1), 152-162, 2012. https://doi.org/10.1016/j.compchemeng.2011.09.011. 